\title{
Mitochondrial fusion and Bid-mediated mitochondrial apoptosis are perturbed by alcohol with distinct dependence on its metabolism
}

\author{
Shamim Naghdi ${ }^{1}$, William S Slovinsky ${ }^{1}$, Muniswamy Madesh, Emanuel Rubin ${ }^{1}$ and György Hajnóczky $\mathbb{B D}^{1}$
}

\begin{abstract}
Environmental stressors like ethanol $(\mathrm{EtOH})$ commonly target mitochondria to influence the cell's fate. Recent literature supports that chronic EtOH exposure suppresses mitochondrial dynamics, central to quality control, and sensitizes mitochondrial permeability transition pore opening to promote cell death. EtOH-induced tissue injury is primarily attributed to its toxic metabolic products but alcoholism also impairs tissues that poorly metabolize EtOH. We embarked on studies to determine the respective roles of $\mathrm{EtOH}$ and its metabolites in mitochondrial fusion and tBidinduced mitochondrial apoptosis. We used HepG2 cells that do not metabolize $\mathrm{EtOH}$ and its engineered clone that expresses EtOH-metabolizing Cytochrome P450 E2 and alcohol dehydrogenase (VL-17A cells). We found that fusion impairment by prolonged EtOH exposure was prominent in VL-17A cells, probably owing to reactive oxygen species increase in the mitochondrial matrix. There was no change in fusion protein abundance, mitochondrial membrane potential or $\mathrm{Ca}^{2+}$ uptake. By contrast, prolonged $\mathrm{EtOH}$ exposure promoted tBid-induced outer mitochondrial membrane permeabilization and cell death only in HepG2 cells, owing to enhanced Bak oligomerization. Thus, mitochondrial fusion inhibition by EtOH is dependent on its metabolites, whereas sensitization to tBid-induced death is mediated by EtOH itself. This difference is of pathophysiological relevance because of the tissue-specific differences in EtOH metabolism.
\end{abstract}

\section{Introduction}

Environmental stressors commonly rewire cellular signaling pathways resulting in either the cell's demise or adaptation supporting survival. Many of these pathways converge on mitochondria, which provide energy and directly control cell survival and ion homeostasis. Mitochondrial dynamics is necessary to maintain mitochondria in optimal condition and mitochondrial membrane integrity is required to support cell survival.

Correspondence: György Hajnóczky (gyorgy.hajnoczky@jefferson.edu) ${ }^{1}$ MitoCare Center, Department of Pathology, Anatomy and Cell Biology, Thomas Jefferson University, Philadelphia, PA, USA

These authors contributed equally to the work: Shamim Naghdi,

William S. Slovinsky

Edited by P. Pinton
Mitochondrial dynamics involves fusion, mediated by MFN $1 / 2^{1}$ and OPA $1^{2}$ and fission, mediated by DRP1 with the assistance of MFF, MID49/51, dynamin 2, and perhaps $\mathrm{FIS1}^{3}$. Fusion mediates the exchange of mtDNA, proteins, and other soluble or membrane components among mitochondria, providing critical support for vital functions such as oxidative phosphorylation, mitophagy, apoptosis, cell proliferation, and migration. Deletion of MFN1/2 or OPA1 in mice is lethal ${ }^{4}$ and mutations in MFN1/2 and OPA1 in humans are linked to nervous system impairments like neuropathy ${ }^{5}$ and dominant optic atrophy ${ }^{6,7}$. Some stressors alter either the amount or the post-translational modification of fusion proteins to

\section{(c) The Author(s) 2018}

(c) (i) Open Access This article is licensed under a Creative Commons Attribution 4.0 International License, which permits use, sharing, adaptation, distribution and reproduction c. in any medium or format, as long as you give appropriate credit to the original author(s) and the source, provide a link to the Creative Commons license, and indicate if changes were made. The images or other third party material in this article are included in the article's Creative Commons license, unless indicated otherwise in a credit line to the material. If material is not included in the article's Creative Commons license and your intended use is not permitted by statutory regulation or exceeds the permitted use, you will need to obtain permission directly from the copyright holder. To view a copy of this license, visit http://creativecommons.org/licenses/by/4.0/. 
perturb the fission/fusion balance, leading to either hyperfusion or fragmentation of mitochondria, which changes help to adjust mitochondrial functions.

Mitochondrial membrane integrity is needed for cell survival since its loss leads to the release of mitochondrial intermembrane space (IMS) content, which compromises energy metabolism and activates death pathways. For instance, mitochondrial $\mathrm{Ca}^{2+}$ overload leads to permeability transition pore (PTP) formation in the inner mitochondrial membrane (IMM) with the ensuing damage of the outer mitochondrial membrane (OMM) leading to cell death ${ }^{8}$. Alternatively, in mitochondrial apoptosis, oligomerization of two pro-apoptotic Bcl-2 family proteins, Bak and Bax results in selective permeabilization of the OMM releasing IMS components like cytochrome c (cyto c), Smac/Diablo to the cytosol activating caspases and other executioner enzymes. Normally, Bak and Bax are neutralized by anti-apoptotic members of the Bcl-2 family like Bcl-2, Bcl-xL, and Mcl-1. However, many stressors target pro-apoptotic members of this family like Bid, Bim, Noxa, or PUMA to activate Bak/Bax directly or indirectly ${ }^{9}$. For instance, TNF $\alpha$ or Fas activates caspase- 8 to truncate Bid, a pro-apoptotic protein to tBid that induces oligomerization of the OMM resident Bak or enhances translocation of the cytoplasmic Bax to the OMM where it also undergoes oligomerization to execute OMM permeabilization (OMMP $)^{10}$. Death of a cell terminates its individual life, but may support survival of the whole organism undergoing stress ${ }^{10}$.

Excessive ethanol (EtOH) consumption causes tissue damage with 2.5 million deaths/year globally ${ }^{11}$. Alcoholic diseases are primarily attributed to the toxic metabolites of $\mathrm{EtOH}$ but more organs are affected than the ones metabolizing $\mathrm{EtOH}$. EtOH metabolites are mainly produced in the liver by two enzymes; alcohol dehydrogenase (ADH) mainly in cytosol and Cytochrome P450 E2 (CYP2E1) in microsomes, producing acetaldehyde. Further, aldehyde dehydrogenase in mitochondria turns acetaldehyde into acetate and then Acetyl-CoA, utilized in mitochondrial metabolism ${ }^{12}$. Acutely EtOH also targets proteins and lipids in membrane and reduces membrane integrity, whereas chronic EtOH (chrEtOH) stiffens the membrane possibly by recruiting cholesterol ${ }^{13}$. Reactive oxygen species (ROS), a byproduct of EtOH metabolism, can denature proteins, break and therefore potentiate DNA to mutate, oxidize lipids, and generate products such as malonaldehyde and 4-hydroxynonenal ${ }^{14}$. These adducts and acetaldehyde, the instant product of $\mathrm{EtOH}$ oxidation, can further interact with biomolecules and modulate their function. Shifting the oxidative state of the mitochondrial matrix may compromise oxidative phosphorylation.

Mitochondria are a primary target for $\mathrm{EtOH}$ toxicity because they oxidize the highly reactive acetaldehyde and generate $\mathrm{ROS}^{15}$. We have shown suppressed mitochondrial fusion in several tissues of EtOH-fed rats ${ }^{16,17}$. As various organs differ in handling $\mathrm{EtOH}$ it is important to study the mitochondrial effects in both metabolizing and non-metabolizing conditions. To test whether the metabolites of $\mathrm{EtOH}$ were involved, we have studied here mitochondrial dynamics in HepG2 cells, which are available both with and without EtOH-metabolizing enzymes. Furthermore, we and others have shown that $\mathrm{EtOH}$ exposure reduces mitochondrial capacity to retain $\mathrm{Ca}^{2+}$ and promotes the $\mathrm{Ca}^{2+}$-induced PTP formation ${ }^{18-20}$ and subsequent membrane potential $\left(\Delta \Psi_{\mathrm{m}}\right)$ dissipation $^{19,20}$. We here investigated the effect of EtOH stress on the Bid/Bak pathway in the HepG2-derived cells.

\section{Results}

\section{ChrEtOH-induced suppression of mitochondrial fusion dynamics depends on ADH and CYP2E1}

We have shown suppressed mitochondrial dynamics in hepatocytes isolated from EtOH-fed rats ${ }^{17}$. To understand whether this phenomenon is dependent on $\mathrm{EtOH}$ metabolism, we used VL-17A, a hepatic cell line derived from HepG2 cells ${ }^{17}$, stably transfected to express ADH and CYP2E1 with high and low affinity to bind and convert EtOH to acetaldehyde (Figure S1). To compare VL-17A with a control, two options were available, the parental HepG2 cells, deficient in ADH and CYP2E1 activity ${ }^{21,22}$ and VI-7 (that carries the empty version of 1 (Zeocinresistance) of the 2 vectors used to create VL-17A) that is $\mathrm{ADH}$ negative ${ }^{23}$. We confirmed the lack of the activity of both ADH and CYP2E1 in VI-7 cells (Figure S1A-D).

We tested both HepG2 and VI-7 cells for mitochondrial morphology and dynamics using mitochondrial matrix-targeted DsRed (mtDsRed) and photo-activatable green fluorescent protein (mtPA-GFP) as described before $^{24,25}$. Based on the fluorescent protein distribution, both HepG2 and VI-7 cells show similar mitochondrial morphology (Figure S2A). After photoactivation, the overall level of mitochondrial dynamic activity, which includes fusion-fission and motility, was assessed by measuring the spreading of the mtPA-GFP from the photo-activated regions (Figure S2B). Because both VI-7 and HepG2 showed almost identical fluorescence spreading, in the rest of the studies of mitochondrial dynamics, we picked only one control, HepG2, to be compared with VL-17A cells.

VL-17A mitochondria were more elongated than HepG2 mitochondria. Chronic exposure to EtOH did not significantly alter mitochondrial morphology in HepG2 cells (Fig. 1c vs a) but shortened and fragmented mitochondria in VL-17A cells (Fig. 1d vs b). To specifically assess fusion state, the initial phase of the mtPA-GFP spreading was inspected because this represents the diffusion of mtPA-GFP among the mitochondria with 


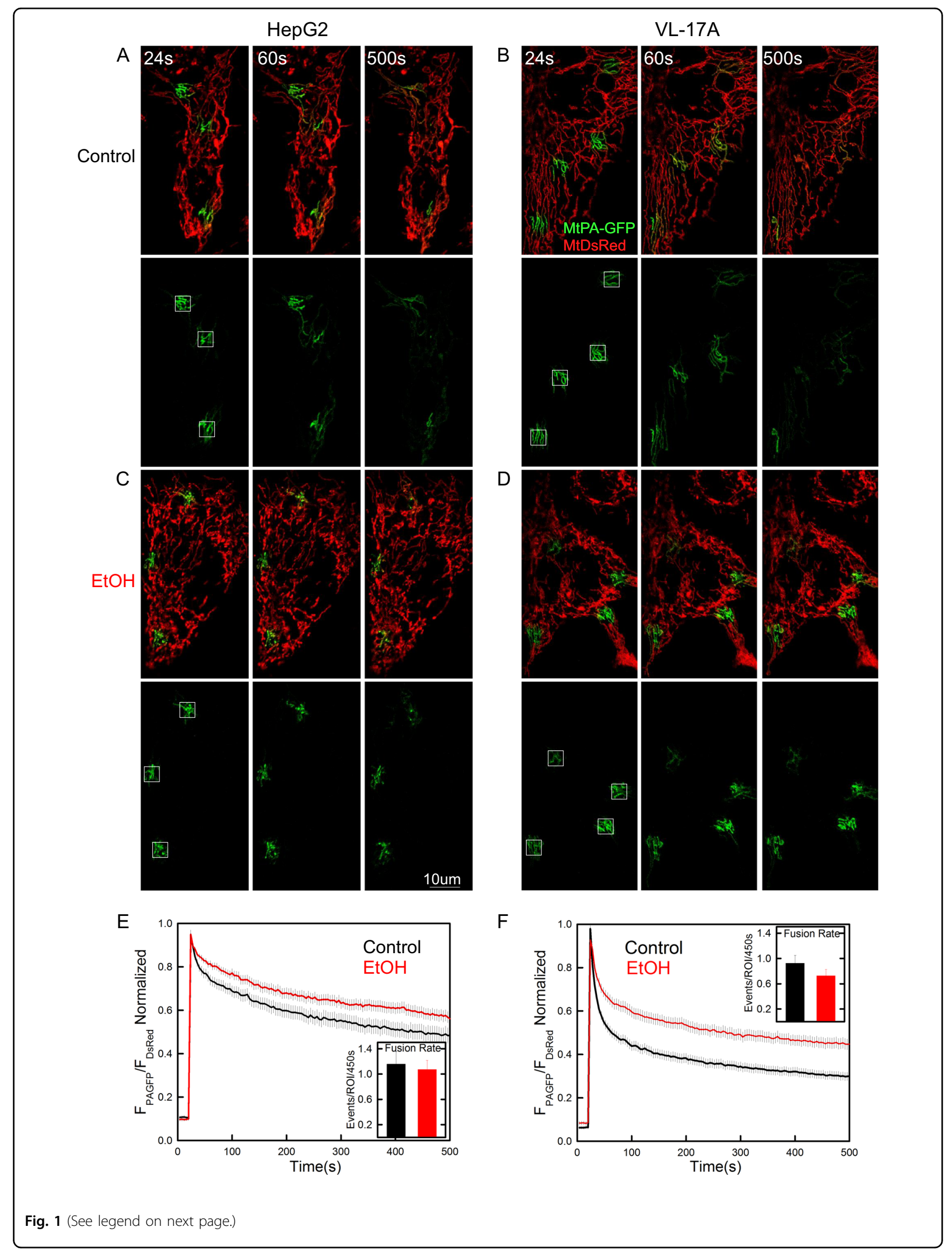


(see figure on previous page)

Fig. 1 ChrEtOH perturbs mitochondrial morphology and dynamics significantly only in VL-17A cells. Cells were transfected with

mitochondrial matrix-targeted DsRed (mtDsRed) and mtPA-GFP. Mitochondrial morphology and GFP spreading after photoactivation in designated areas are shown for a typical control HepG2 $\mathbf{a}$ and $\mathrm{VL}-17 \mathrm{~A}$ cells $\mathbf{b}$ or the cells chronically treated with $\mathrm{EtOH} \mathbf{c}$, $\mathbf{d}$. In the lower panels, only the green channel is shown. e, $\mathbf{f}$ Spreading rate of GFP after photoactivation has been quantified and presented as the normalized ratio of mtPA-GFP to mitoDsRed in the photo-bleached regions. $\mathbf{e}, \mathbf{f}$ fusion rates were presented as the mean number of fusion events that calculated manually in the region of interests (ROI) for 450 s. e $n$ for control and EtOH is 27 and 29; $\mathbf{f} n$ for both HepG2 and EtOH is 37) $(n=4)$

continuous matrix. The spreading appeared slightly slower in the EtOH-treated HepG2 and markedly suppressed in the EtOH-treated VL-17A cells, indicating suppression of dynamics (Fig. 1e, f). To quantitatively compare the EtOH effect on both network continuity and fusion activity in the two cell lines, mtPA-GFP spreading values were compared at $156 \mathrm{~s}$. Two-way analysis of variance (ANOVA) confirmed that: (1) untreated HepG2 shows slower spreading than untreated VL-17A $(p<0.001)$; (2) the effect of EtOH was significant only in VL-17A (HepG2: $p=0.09$, VL-17A: $p<0.001$ ); and (3) the effect of EtOH was significantly larger in VL-17A than in HepG2 cells ( $p<0.001$, Figure S2C black bars), indicating that the effect of chrEtOH depends on the presence of EtOH-metabolizing enzymes. To further assess mitochondrial fusion, the individual events were manually counted ${ }^{24,25}$. This revealed similar fusion activity in both HepG2 and VL-17A cells, and upon chrEtOH treatment, a decrease appeared in VL-17A cells but it was not significant (Fig. 1e, f).

\section{Application of EtOH metabolism-altering agents restores mitochondrial dynamics}

To validate that the effect chrEtOH on mitochondrial dynamics was promoted by its metabolism, both HepG2 and VL-17A cells were treated either with 4methylpyrazole (4-MP), an $\mathrm{ADH}$ enzyme inhibitor or ALDA-1, an agonist for aldehyde dehydrogenase 2 (ALDH2) simultaneous with chrEtOH treatment. In the presence of 4-MP, the EtOH effect was unaltered in HepG2 cells (Fig. 2c vs a, S2C), but was attenuated in VL17A cells (Fig. $2 d$ vs b, S2C). Similarly, treatment of the cells with ALDA-1 did not cause a change in HepG2 cells (Fig. 2e, S2C) but prevented the EtOH effect in VL-17A cells (Fig. 2f, S2C). Thus, any of the 2 agents interfering with $\mathrm{EtOH}$ metabolism showed rescue of mitochondrial dynamics in EtOH-treated VL-17A cells. Collectively, these results indicate that suppression of mitochondrial dynamics by $\mathrm{EtOH}$ is directly dependent on the activity of $\mathrm{ADH}$ and CYP2E1 enzymes and probably on acetaldehyde/ROS as the major $\mathrm{EtOH}$ metabolite/byproduct. Notably, both 4-MP and ALDA-1 suppressed fluorescent protein spreading by borderline significance in non-treated VL-17A cells $(p=0.043$ and $p=0.05)$, suggesting that the basal level enzyme activity of ADH and CYP2E1
(Figure S1) and the pathway targeted by the drugs has some stimulatory effect on mitochondrial dynamics.

\section{EtOH treatment enhances ROS in mitochondria in VL-17A cells to reduce mitochondria dynamics}

To determine whether ROS levels are differently affected by prolonged EtOH exposure in HepG2 and VL-17A, and to evaluate the subcellular localization of ROS, cells were transfected with a genetically encoded probe, Grx1roGFP2, that measures the ratio of oxidized glutathione (GSSG) to reduced glutathione (GSH), targeted either to the cytoplasm or mitochondrial matrix. The fluorescence ratio of Grx1-roGFP2 specifically measures GSSG/ $\mathrm{GSH}$, reflecting ROS levels. As references, dithiothreitol (DTT) was used to determine the fully reduced and $\mathrm{H}_{2} \mathrm{O}_{2}$ to obtain the maximally oxidized states. A representative graph is shown in Fig. 3a and the baseline fluorescence ratios normalized to the range between DTT and $\mathrm{H}_{2} \mathrm{O}_{2}$ are shown for the cytoplasm in Fig. $3 \mathrm{~b}$ and for the mitochondrial matrix in Fig. 3c. The cytoplasmic Grx1roGFP2 signal indicated a more oxidizing environment in the VL-17A than in the HepG2 cells (Fig. 3b). Neither chronic (Fig. 3b) nor acute EtOH (Figure S2D) changed the baseline level of cytoplasmic ROS in HepG2 and VL-17A cells. The mitochondrial Grx1-roGFP2 signal was similar in HepG2 and VL-17A cells in the absence of $\mathrm{EtOH}$, and was unaffected by acute $\mathrm{EtOH}$ addition (Figure S2E). However, chrEtOH treatment created a more oxidizing environment in the mitochondrial matrix of VL-17A cells compared with HepG2 cells (Fig. 3c). These results suggest that $\mathrm{EtOH}$ metabolism to acetate is associated with ROS production that causes an oxidative shift in the mitochondrial matrix, whereas in the absence of $\mathrm{ADH}$ and CYP2E1, ROS generation is undetectable. To test whether the ROS are relevant in the attenuation of mitochondrial fusion, a vitamin E-derived ROS scavenger, Trolox, was used. Trolox rescued the EtOHinduced suppression in VL-17A cells (Fig. 4), indicating that ROS is responsible for suppression of mitochondrial dynamics by prolonged EtOH in VL-17A cells.

\section{ChrEtOH does not alter $\Delta \Psi_{\mathrm{m}}$ and $\mathrm{Ca}^{2+}$ uptake or the abundance of fusion proteins}

Because both mitochondrial fusion and motility are affected by $\Delta \Psi_{\mathrm{m}}$ and $\mathrm{Ca}^{2+25,26}$, we hypothesized that 


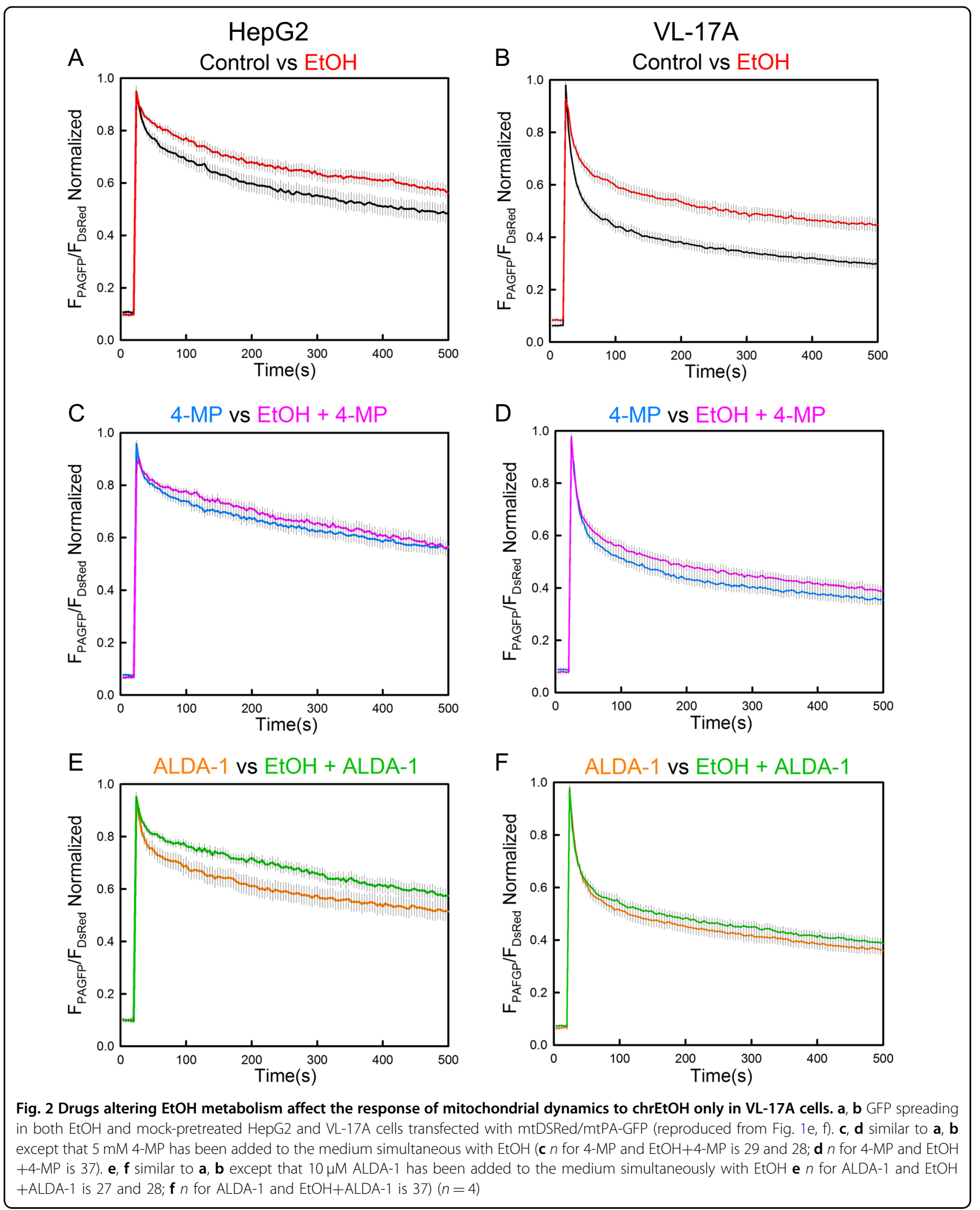




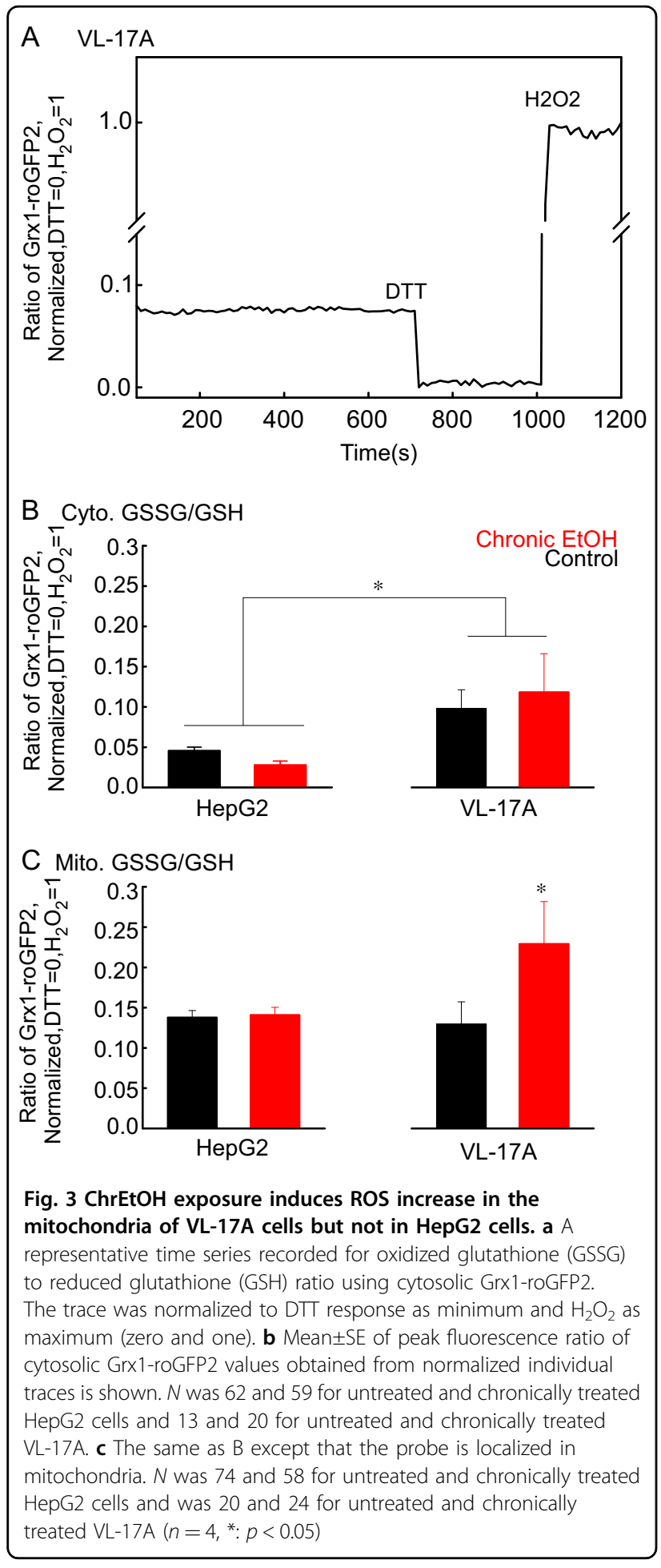

these factors might be involved in the suppression of mitochondrial dynamics. First, we compared $\Delta \Psi_{\mathrm{m}}$ values, before and after mitochondrial $\mathrm{Ca}^{2+}$ uptake in VL-17A and HepG2 cells. Both HepG2 and VL-17A cells showed similar $\Delta \Psi_{\mathrm{m}}$ before and after $\mathrm{Ca}^{2+}$ addition, and no change in $\Delta \Psi_{\mathrm{m}}$ occurred when they were exposed to
EtOH (Fig. 5a). Mitochondrial $\mathrm{Ca}^{2+}$ uptake was also unaffected by chrEtOH (Fig. 5b).

We also investigated if $\mathrm{EtOH}$ metabolites or generated ROS might affect the levels of the fusion proteins. Western blots (Fig. 5c) and the quantification of relevant bands (Figure S3) showed no decrease in the abundance of Mfn1/2, Opa1 in HepG2 and VL-17A cell lines exposed chronically to EtOH. Thus, EtOH-induced ROS suppresses mitochondrial fusion dynamics independent of $\Delta \Psi_{\mathrm{m}}, \mathrm{Ca}^{2+}$ handling and the abundance of fusion proteins.

We have already shown that ROS can sensitize cells to tBid-induced $\mathrm{OMMP}^{27}$. Based on the above results, we were wondering whether $\mathrm{EtOH}$ also sensitizes the cells to tBid primarily through its metabolism. We first set out to study the effect of EtOH on HepG2 cells that we considered as a "negative control" because of the lack of ADH and CYP2E1 enzyme activity ${ }^{21,22}$.

\section{EtOH sensitizes HepG2 and heart-derived H9c2 cells to tBid-induced OMMP and cell death}

To study the direct effect of $\mathrm{EtOH}$ on tBid-induced cell death, HepG2 cells were pretreated with either 0 or $100 \mathrm{mM}$ EtOH for $72 \mathrm{~h}$. Zero or $30 \mu \mathrm{M}$ cell permeable Bid $\mathrm{BH} 3$ peptide (Bid BH3cp) ${ }^{28}$ was added to each in the last $2 \mathrm{~h}$ before cell viability was tested. Viability was reduced by $\sim 20 \%$ in cells exposed to either EtOH or Bid BH3cp alone, and by $\sim 60 \%$ when Bid BH3cp was added to the cells that were pretreated with $\mathrm{EtOH}$, indicating that unexpectedly, EtOH independent of its metabolism, sensitizes the cells to tBid-induced cell death (Fig. 6a).

To study the involvement of mitochondria directly, tBid was added to $\mathrm{EtOH}$-pretreated and untreated plasma membrane-permeabilized HepG2 cells in suspension. tBid-induced OMMP was measured as cytochrome c (cyto c) redistribution from mitochondria to cytosol and $\Delta \Psi_{\mathrm{m}}$ collapse measured in the presence of oligomycin. Addition of a high concentration of tBid, $100 \mathrm{nM}$, resulted in a complete $\Delta \Psi_{\mathrm{m}}$ loss with half-maximal response $\sim 50 \mathrm{~s}$ in both EtOH-pretreated and untreated cells (Fig. 6b). Addition of $2.5 \mathrm{nM}$ and less tBid caused delayed $\Delta \Psi_{\mathrm{m}}$ dissipation with a slower rate (Fig. 6c). Under this condition, $\Delta \Psi_{\mathrm{m}}$ dissipates faster in EtOH-treated cells compared with naive. The difference between $\mathrm{EtOH}$-treated and untreated cells was more striking at lower tBid concentrations (i.e., $0.5 \mathrm{nM}$ and $0.25 \mathrm{nM}$ ). In fact, this concentration of tBid caused mitochondrial depolarization only in EtOH-pretreated cells (Fig. 6c). Figure 6d shows the tBid dose-response relationship for both untreated cells and EtOH-pretreated ones and reveals a leftward shift in the EtOH condition. To study the distribution of cyto c, cytosolic and membrane fractions were separated and the purity of each fraction was assessed by $\alpha$-Tubulin, mitochondrial HSP70, and Prohibitin as cytosolic or 

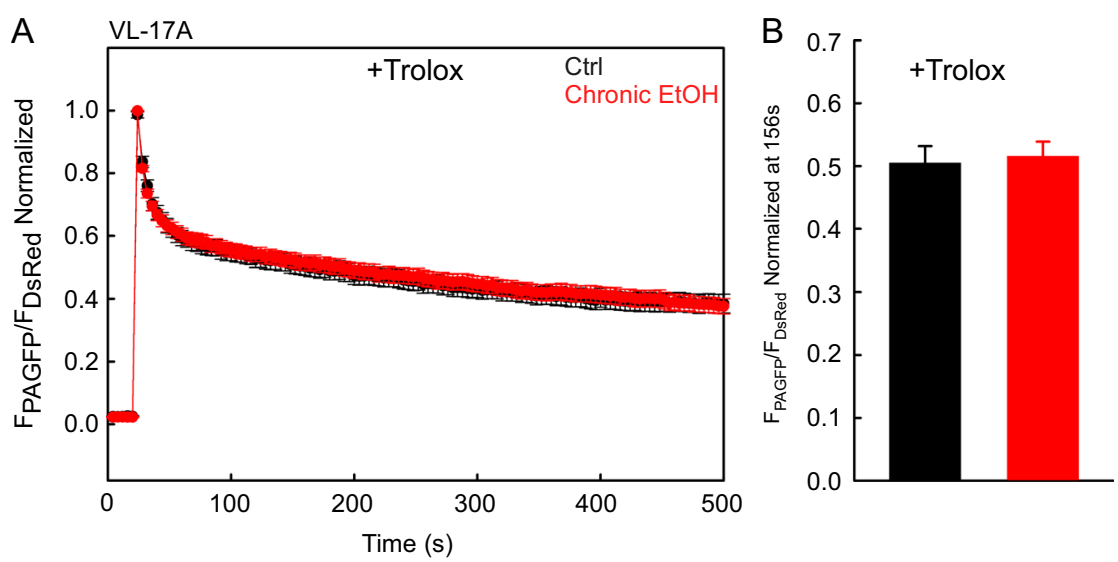

Fig. 4 Trolox abolishes the effect of chrEtOH on mitochondrial dynamics in VL-17A cells. a Mean traces of time lapse of mtPA-GFP spreading in both EtOH and mock-exposed VL-17A cells, which were treated with $50 \mu \mathrm{M}$ Trolox. b Mean value of mtPA-GFP spreading at $156 \mathrm{~s}$. N was 34 and 38 for EtOH-treated and untreated cells $(n=3)$
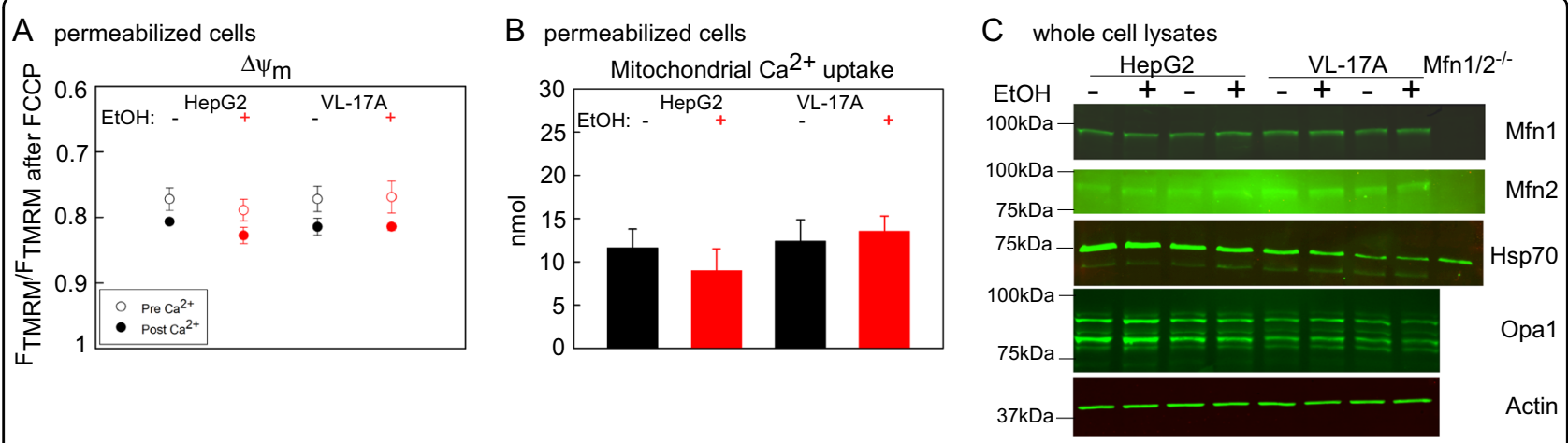

Fig. $5 \Delta \Psi \mathrm{m}, \mathrm{Ca}^{2+}$ handling, and the abundance of the mitochondrial fusion proteins are unchanged in chronically EtOH-treated VL-17A and HepG2 cells. a $\Delta \Psi_{m}$ before and after the addition of $\mathrm{Ca}^{2+}$ were presented as the fluorescent intensity of TMRM normalized to the TMRM fluorescent intensity obtained after complete depolarization by FCCP $(5 \mu \mathrm{M})$ in permeabilized cell suspensions $(n=3)$. b Mitochondrial $\mathrm{Ca}^{2+}$ uptake was measured using Fura2FF and the data presented as the $\mathrm{nmol} \mathrm{Ca}{ }^{2+}(n=3)$. c Western blot for Mfn1/2 and Opa1 in the cell lysates of VL-17A and HepG2 cells, which were chronically treated with EtOH. Actin was used as loading control $(n=3)$

mitochondrial marker (Figure S4A). Western blot analysis of cytosolic fractions confirmed that addition of high tBid for 5 min results in similar cyto c release in both $\mathrm{EtOH}$ and untreated cells (Fig. 6e). Because the release of cyto $\mathrm{c}$ is an earlier event than the $\Delta \Psi_{\mathrm{m}}$ collapse, whereas $\mathrm{EtOH}$-treated cells showed higher sensitivity to $\Delta \Psi_{\mathrm{m}}$ collapse after addition of $2.5 \mathrm{nM}$ tBid for $5 \mathrm{~min}$, both EtOH-exposed and non-exposed cells showed similar cyto c release (Fig. 6e). With lower concentrations of tBid $(0.25$ and $0.5 \mathrm{nM})$ in short/long time points, a larger fraction of cyto $c$ was released in the EtOHpretreated samples (Fig. 6). To assess whether EtOH favors the release of multiple IMS pro-apoptotic proteins, Smac/Diablo release was also tested in the tBid-treated samples using western blot. High concentrations of tBid $(2.5,100 \mathrm{nM}$ for $5 \mathrm{~min})$ released Smac/Diablo similarly in both $\mathrm{EtOH}$ and mock-pre-exposed samples but in response to a submaximal concentration of tBid $(0.5 \mathrm{nM})$ the EtOH-preexposed sample showed more release of Smac (Figure S4B). Collectively, these results show that EtOH sensitizes HepG2 cells to tBid-induced OMMP and release of multiple IMS proteins.

To test whether this phenomenon is cell line specific, we pretreated rat cardiac myoblasts, H9c2 cells, with $\mathrm{EtOH}$ for $72 \mathrm{~h}$. H9c2 cells are more sensitive to tBid than HepG2 cells. As Figure S4C shows, a maximally effective dose of $2.5 \mathrm{nM}$ tBid (as high concentration) caused $\Delta \Psi_{\mathrm{m}}$ dissipation with similar onset and kinetics in EtOHpretreated or control cells with half-maximal response around $50 \mathrm{~s}$. However, similar to HepG2 cells, a subthreshold concentration of $\mathrm{tBid}(0.032 \mathrm{nM})$ for the control caused $\Delta \Psi_{\mathrm{m}}$ loss in 40 or $80 \mathrm{mM}$ EtOH-pretreated cells (Figure S4D). The velocity of depolarization depended on the $\mathrm{EtOH}$ concentration. Accordingly, low doses of tBid 


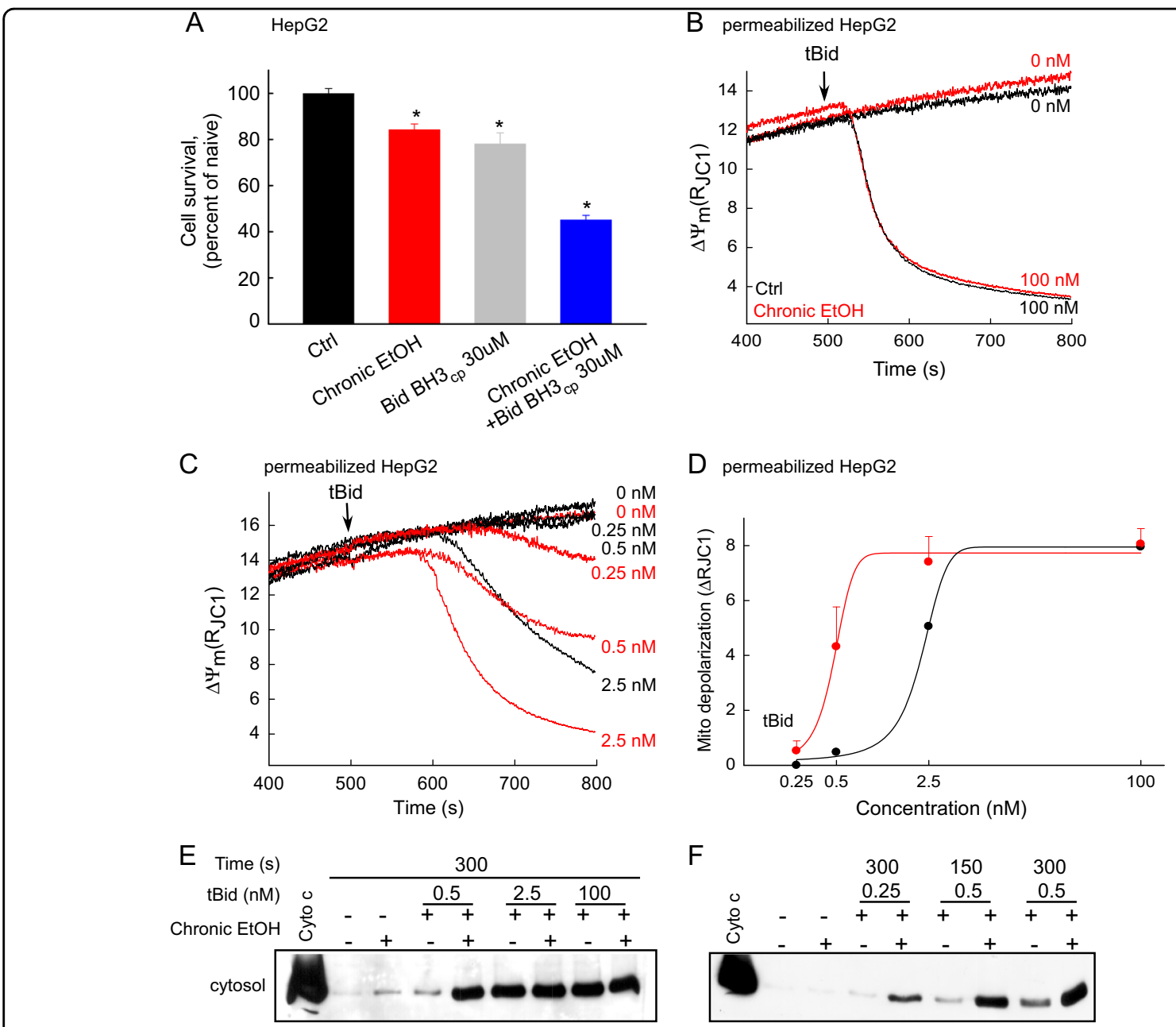

Fig. 6 EtOH sensitizes HepG2 cells to tBid-induced OMMP. a Cell viability was tested for $100 \mathrm{mM} \mathrm{EtOH}$ and/or $30 \mu \mathrm{M}$ Bid BH3 $3_{\mathrm{cp}}$-treated intact HepG2 cells $\left(n=4,{ }^{*} p<0.05\right)$. b Time-course recording of $\Delta \Psi_{\mathrm{m}}$ in permeabilized HepG2 cell suspension using fluorometer. $0,100 \mathrm{nM}$ tBid was added at $500 \mathrm{~s}$. Red traces represent EtOH-treated cells and black traces non-treated ones. $\mathbf{c}$ Similar to $\mathbf{b}$ except lower concentrations of tBid $(0,2.5,0.5$, and $0.25 \mathrm{nM})$ were used $(n=3)$. $\mathbf{d}$ Dose-response relationship between tBid concentration and $\Delta \Psi_{\mathrm{m}}$ dissipation in HepG2 permeabilized cells. e Immunoblot of cyto $\mathrm{c}$ in the cytosolic fraction of the permeabilized cells that were separated quickly from pellet fraction right after $300 \mathrm{~s}$ treatment with tBid or solvent. Cyto $\mathrm{c}$ was loaded as a positive control. f Similar to e except the treatment times were either $300 \mathrm{~s}$ or $150 \mathrm{~s}$

release cyto c only in EtOH-treated cells (Figure S4E). Thus, EtOH promotes tBid-induced OMMP in both HepG2 and a cell line derived from a tissue with little capacity to metabolize EtOH.

\section{EtOH sensitizes to tBid through Bcl-2 family proteins and independent of PTP opening}

To test whether the EtOH-mediated sensitization effect requires PTP opening, we repeated the experiments shown in Fig. 6b both in the presence or absence of cyclosporine A (CSA), a PTP inhibitor (Fig. 7a). CSA failed to influence the onset or velocity of tBid-induced $\Delta \Psi_{\mathrm{m}}$ depolarization. To clarify if the effect of EtOH was mediated through Bcl-2 family proteins we used recombinant $\mathrm{Bcl}-\mathrm{xL}^{29}$. Addition of anti-apoptotic $\mathrm{Bcl}-\mathrm{xL}$ $(2 \mu \mathrm{M})$ repressed tBid-induced $\Delta \Psi_{\mathrm{m}}$ loss in both the presence and absence of EtOH (Fig. 7a). Immunoblotting against cyto $\mathrm{c}$ and Smac showed that the tBid-induced cyto $\mathrm{c} / \mathrm{Smac}$ relocation to the cytoplasm in both EtOHexposed and non-exposed cells was unaffected by CSA treatment (Fig. $7 \mathrm{~b}$ ) and was blocked by Bcl-xL addition. Collectively, this shows that $\mathrm{EtOH}$ does not engage in PTP formation and likely facilitates pro-apoptotic Bcl-2 family proteins to respond to tBid.

\section{EtOH does not alter DRP1 expression or localization}

$\mathrm{DRP}^{30,31}$ and OPA1 proteins ${ }^{32}$ both are associated with the control of cyto $c$ release. We have already shown that 


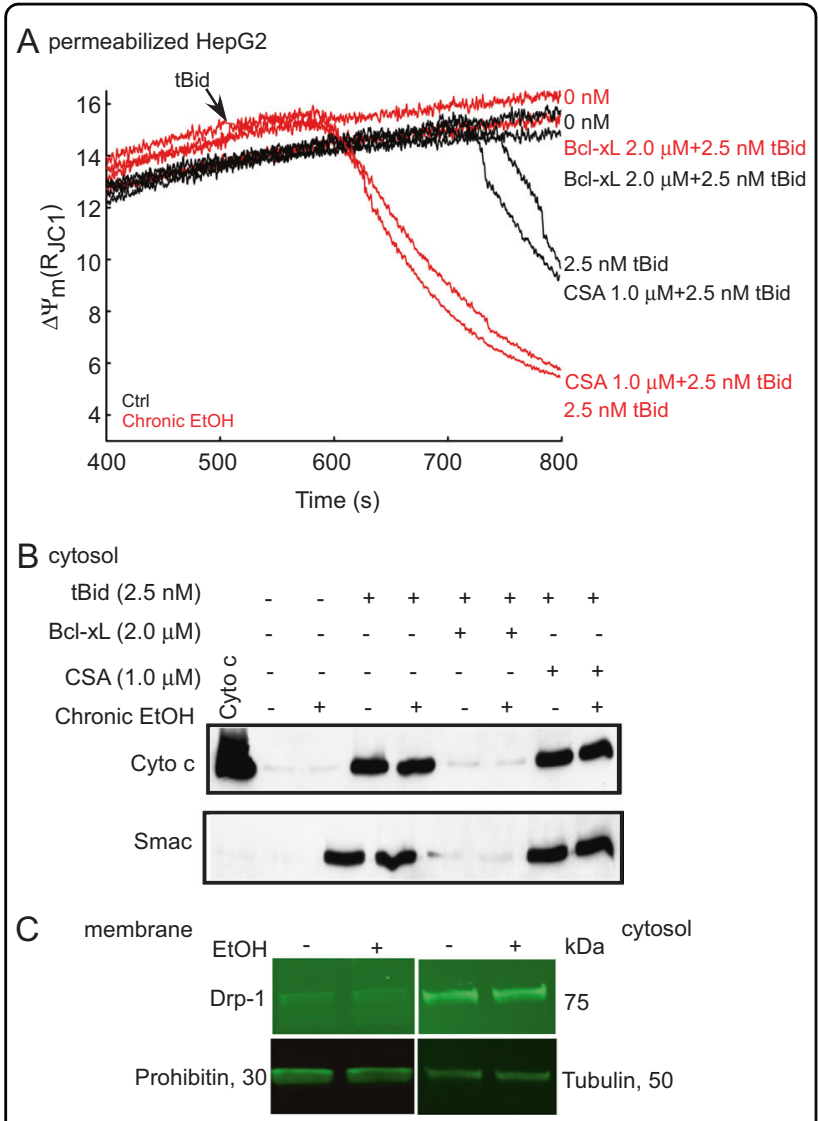

Fig. $7 \mathrm{Bcl}-x \mathrm{~L}$ desensitizes mitochondria to tBid-induced permeabilization independent of EtOH presence and CSA has no influence on EtOH-mediated sensitization to tBid. a Time-course recording of $\Delta \Psi_{m}$ in the permeabilized HepG2 cells suspensions treated with $1 \mu \mathrm{M}$ CSA or $2.5 \mathrm{nM} \mathrm{BCl-xL}$. tBid $(0$ or $2.5 \mathrm{nM})$ was added at $500 \mathrm{~s}$. Arrow shows the tBid addition. Red lines represent $100 \mathrm{mM}$ EtOH-pretreated, and black lines mock-treated cells $(n=3)$. b Western blot of cyto $\mathrm{c}$ and Smac/Diablo in the cytosolic fraction of the samples that were treated with $1 \mu \mathrm{M}$ CSA, $2.5 \mathrm{nM} \mathrm{BCl-xL}$ and tBid (0 or $2.5 \mathrm{nM}$ ) for $5 \mathrm{~min}$. Cyto $\mathrm{c}$ was loaded as positive control. c Immunoblot of Drp1 in the membrane/cytosolic fraction of permeabilized HepG2 cells. Tubulin and Prohibitin were used as loading controls

EtOH does not alter OPA1 level (Fig. 5c and S3) and we show in Fig. 7c that DRP1 was mainly in the cytosolic fraction of HepG2 cells and its abundance was unaffected by prolonged $\mathrm{EtOH}$ exposure.

\section{EtOH-dependent sensitization of tBid-induced OMMP is insensitive to ROS scavenging by Trolox}

As shown in Fig. 3, there is no change in the ratio of GSSG to GSH in EtOH-treated HepG2 cells suggesting that global ROS was not increased; however, this did not exclude a local ROS increase close to the mitochondria. To test the involvement of ROS, cells were pretreated with/without $50 \mu \mathrm{M}$ Trolox simultaneously with EtOH. Treatment with Trolox failed to suppress EtOH's effect on tBid-induced cyto $\mathrm{c}$ release and mitochondrial depolarization (Fig. 8a-c). In fact, Trolox exerted some sensitization to tBid-induced OMMP both in the absence and presence of $\mathrm{EtOH}$ treatment. This set of data further supports that the influence of EtOH on OMMP is not mediated through ROS.

\section{Prolonged exposure to EtOH is required to sensitize tBid- induced OMMP}

Next, we studied whether EtOH acts instantaneously or long-term EtOH exposure was needed. HepG2 cells were exposed to both chrEtOH $(72 \mathrm{~h})$ and acute EtOH and $\Delta \Psi_{\mathrm{m}}$ and cyto $\mathrm{c}$ release were recorded upon tBid treatment. Although chrEtOH sensitized cells to tBid, acute exposure failed to show any effect on tBid-induced OMMP (Fig. 8d-f).

\section{EtOH's facilitation of the tBid pathway is independent of its metabolism}

To test whether metabolism of EtOH enhances the sensitization to tBid we studied VI-7 and VL-17A cells. As shown before for HepG2 (Figs. 6-8), EtOHpretreatment of VI-7 resulted in higher tBid-induced depolarization velocity and cyto c release (Fig. 9a, c, d). Untreated VL-17A were more sensitive to tBid than VI-7, but unexpectedly, $\mathrm{EtOH}$ failed to sensitize tBid-induced OMMP (Fig. 9b-d) and actually, in this condition EtOHexposed VL-17A showed slower depolarization and less cyto $c$ release (Fig. 9d). When the tBid treatment was more prolonged (480 s), both HepG2 and VL-17A showed a similar level of cyto $\mathrm{c}$ in the presence or absence of $\mathrm{EtOH}$.

To further explore this, we studied whether $\mathrm{EtOH}$ promoted the interaction of $\mathrm{tBid}$ with the OMM. Western blotting against Bid (Fig. 9e), showed similar amounts of the added tBid in the membrane fraction of $\mathrm{EtOH}$ exposed and non-exposed cells, indicating that tBid interaction with the membrane was unchanged by $\mathrm{EtOH}$. Using a cross-linker, we found that tBid-induced OMMP is mainly the result of Bak and not Bax oligomerization in VI-7 and that EtOH exposure increases Bak oligomerization in this cell type (Fig. 9f). By contrast, EtOHexposed VL-17A showed lesser Bak oligomerization compared with the controls. In addition, only in VL-17A, tBid induced Bax oligomerization, which was suppressed in EtOH-exposed VL-17A (Fig. 9f, lower).

Finally, we asked if $\mathrm{EtOH}$ treatment would alter the amount of Bcl-2 family proteins required to sensitize cells to $\mathrm{tBid}$. Most of the relevant Bcl-2 family members in the tBid-OMMP pathway (Bak, Bcl-xL, and Mcl-1) did not show any differences in the protein levels (Fig. 9g). One exception is that Bax levels were relatively high in untreated VL-17A cells, and that was reduced after EtOH treatment (Fig. 9g, S5A). Another mechanism for the sensitizing effect of chrEtOH could be an elevation 

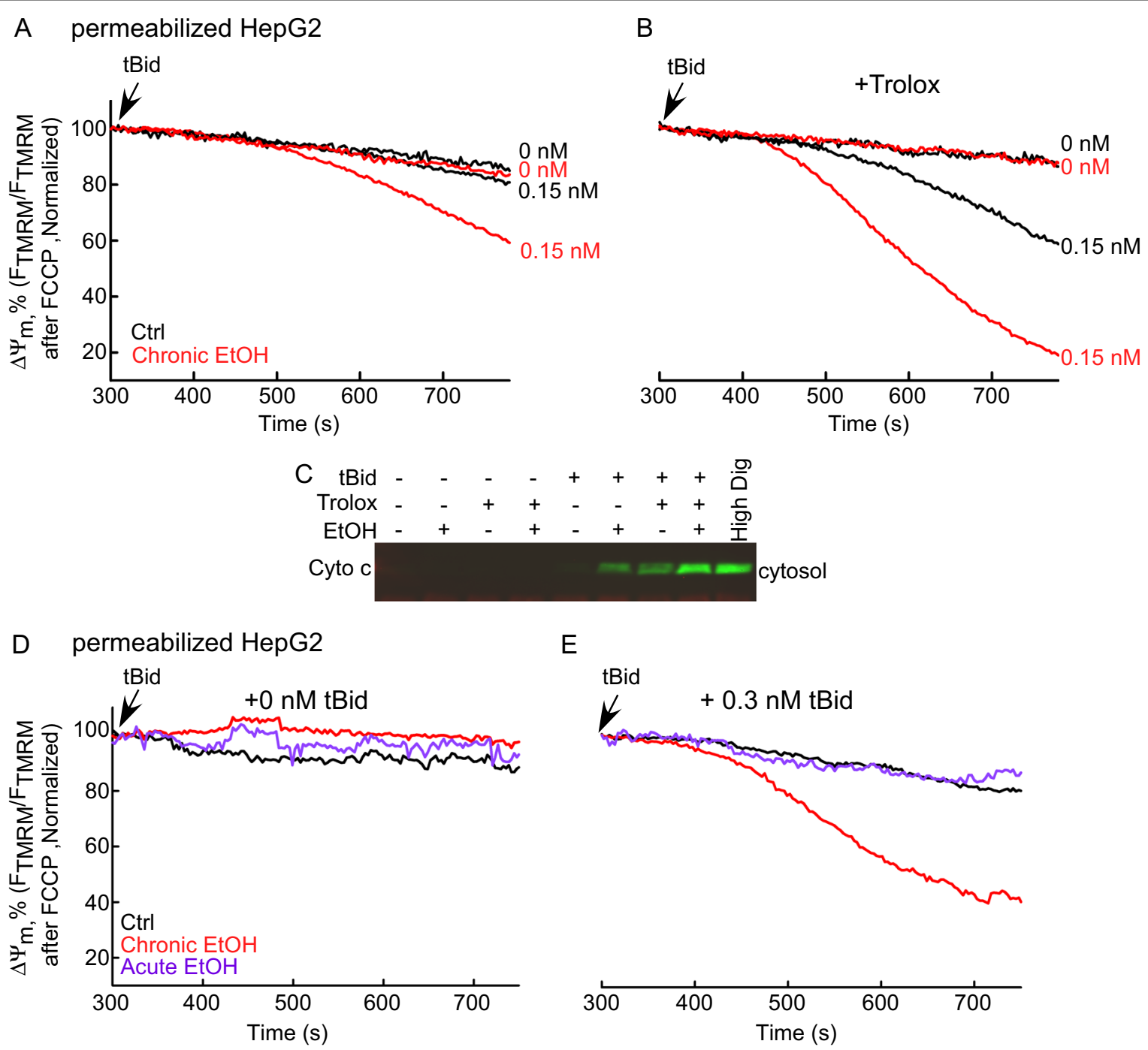

E
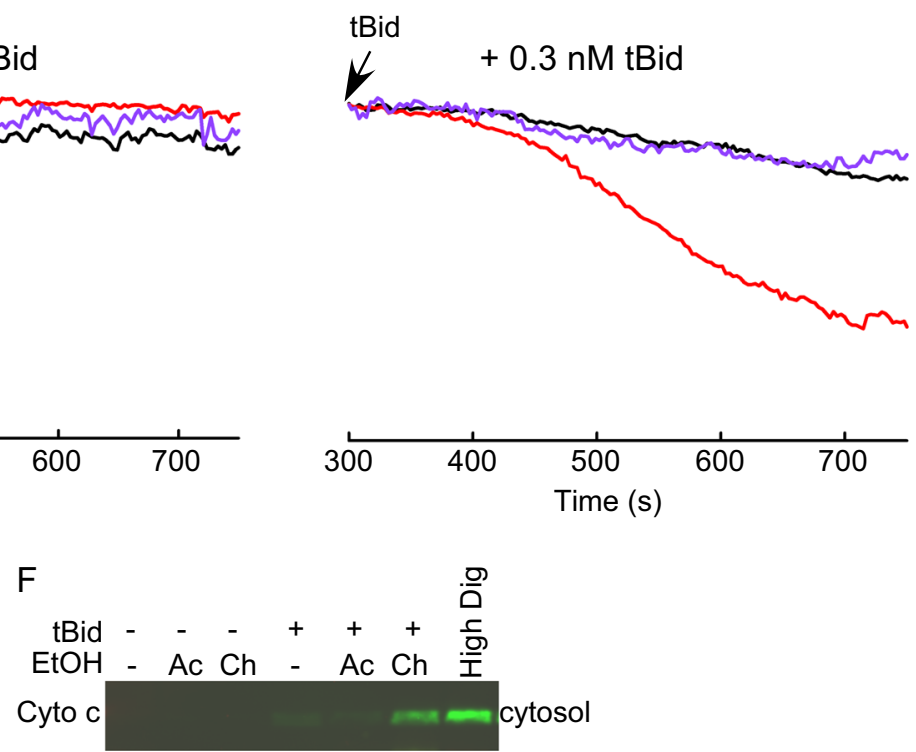

Fig. 8 Trolox does not alter the EtOH-dependent sensitization of tBid-induced OMMP in HepG2 cells. Only chrEtOH sensitizes the cells to tBid. a Time-course graph of $\Delta \Psi_{\mathrm{m}}$ in 0 and $100 \mathrm{mM}$ EtOH-exposed permeabilized HepG2 cells. tBid $(0$ and $0.15 \mathrm{nM})$ was added at $300 \mathrm{~s}$. Similar to Fig. $6 \mathrm{~b}$, at the end of each experiment, FCCP was added. The data are presented as the percentage of the initial $\Delta \Psi_{\mathrm{m}}$. Arrow shows the tBid addition. $\mathbf{b}$ Similar as $\mathbf{a}$, except that the cells have been treated with $50 \mu \mathrm{M}$ Trolox for $72 \mathrm{~h}$ before the experiment and was refreshed every $24 \mathrm{~h}(n=3)$. c Western blot of cyto $\mathrm{c}$ in the cytosolic fraction of the HepG2 permeabilized samples, which were separated from the pellet at the end of each run. High concentration $(600 \mathrm{\mu g} / \mathrm{ml})$ of Digitonin was used to release all the cyto $\mathrm{c}$ in the mitochondria as positive control. d, e Mean traces of time-course recording of $\Delta \Psi_{\mathrm{m}}$ in permeabilized HepG2 cells suspension in cells chronically or acutely exposed to $100 \mathrm{mM}$ ethanol $(n=3)$. tBid concentration was either zero $\mathbf{d}$ or $0.3 \mathrm{nM}$ e. At the end of each experiment, FCCP $(5 \mu \mathrm{M})$ was added to depolarize the remaining $\Delta \Psi_{\mathrm{m}}$. The data are presented as the percentage of the initial $\Delta \Psi_{\mathrm{m}}$. Arrow shows the tBid addition. Black, red, and purple traces are control, chronically and acutely EtOH-treated in order. f Western blot of cyto c

of endogenous tBid or Bim, which might occupy the anti-apoptotic Bcl-2 family proteins. However, quantification of BimEL, BimL, BimS, and tBid showed no change upon $\mathrm{EtOH}$ treatment (Figure S5B).
Collectively, the results on HepG2/VI-7 vs VL-17A indicate that $\mathrm{EtOH}$ sensitizes tBid-induced OMMP independent of $\mathrm{EtOH}$ metabolism and changes in levels of $\mathrm{Bcl}-2$ family proteins. The effect of $\mathrm{EtOH}$ is downstream 


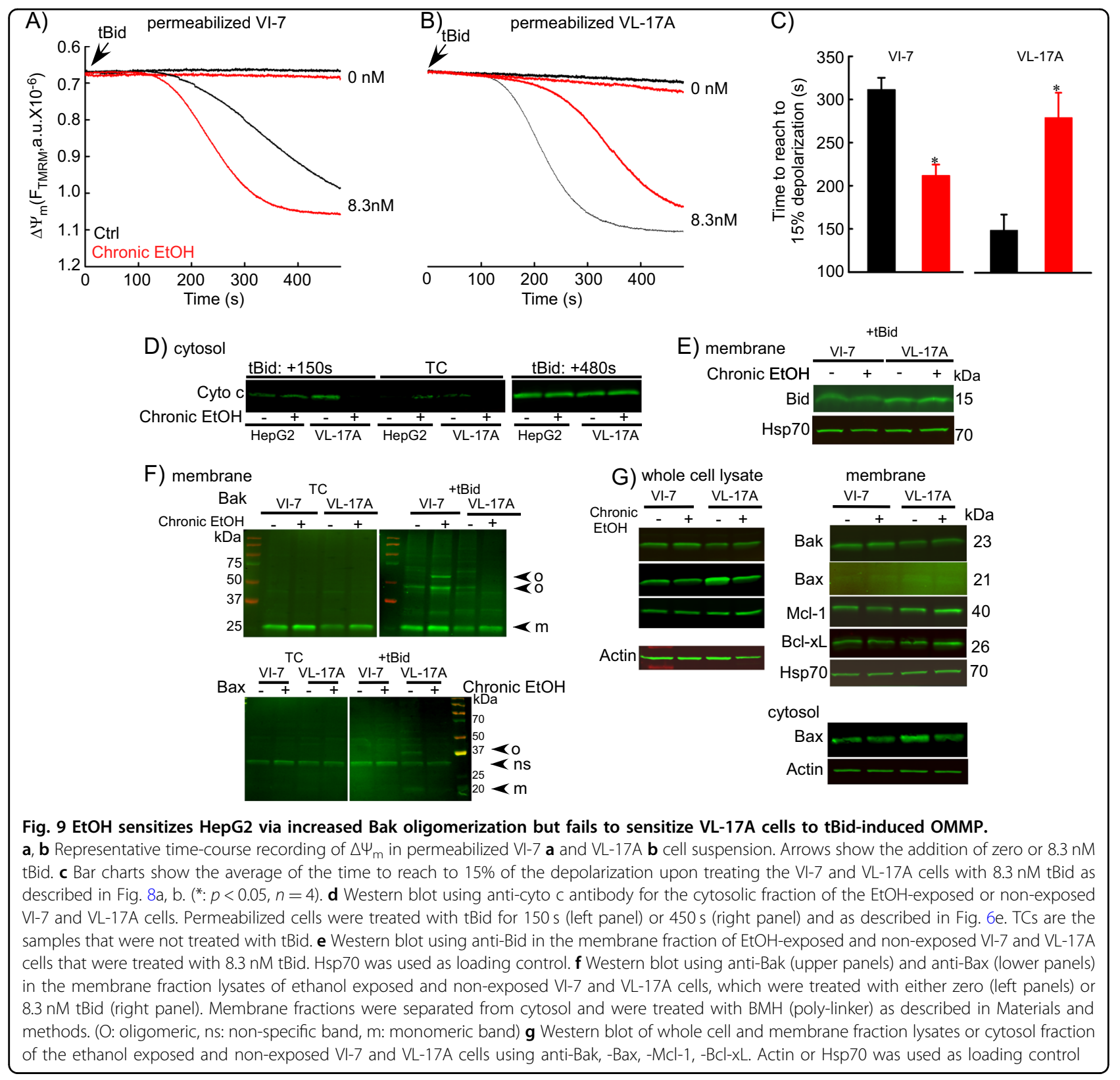

of tBid association to the OMM, and likely occurs at the level of Bak oligomerization. Furthermore, the results also revealed a relatively high tBid sensitivity in VL-17A cells possibly owing to higher Bax abundance and tBid-induced Bax oligomerization. Unexpectedly, only in the EtOHmetabolizing condition, Bax was downregulated, and both Bak and Bax oligomerization are attenuated.

\section{Discussion}

We studied the effect of EtOH-induced stress on mitochondrial fusion and mitochondrial apoptosis in VL17A cells that serve as a simplified model of hepatocytes, and HepG2/VI-7 cells lacking the EtOH-metabolizing enzymes. Previously, the effect of chrEtOH on intracellular signaling and dynamics was investigated mainly in EtOH-fed animal models, in which $\mathrm{EtOH}$ effects might be influenced by several other factors or in cell lines that do not metabolize EtOH. The present paradigm allows direct application of $\mathrm{EtOH}$ to cell types, which are identical except the difference in EtOH-metabolizing enzymes.

We showed that EtOH metabolism in VL-17A leads to ROS elevation in the mitochondrial compartment but in HepG2, EtOH fails to increase mitochondrial ROS. As the ROS elevation is confined to the mitochondria, the reason of ROS elevation can be an increase in the respiratory chain activity, change in the redox state 
(change in NAD/NADH ratio) and reduction of antioxidants-like superoxide dismutase ${ }^{33}$ and elevation of Glutamate dehydrogenase activity ${ }^{34}$. Using a ROS scavenger, we linked EtOH-induced suppression of mitochondrial dynamics to ROS generation.

We documented that mitochondrial fusion is suppressed in VL-17A cells upon chrEtOH similar to hepatocytes ${ }^{17}$ without a change in fusion protein levels. Therefore, we reason that a change in the lipid membrane or translated fusion proteins or mitochondrial positioning affected fusion activity. ROS elevation might result in lipid peroxidation or addition of residues (like HNE) to lipids followed by alteration in the physiochemical properties of the membranes. Evidence has been presented that $\mathrm{EtOH}$ causes modification of cardiolipin in the liver $^{35,36}$. Cardiolipin has also been described as a factor required for both OPA1-mediated IMM fusion ${ }^{37}$ and MFN-mediated OMM fusion ${ }^{38}$. In addition, cardiolipin interacts with DRP1 to facilitate fission ${ }^{39}$, and is needed for crista formation ${ }^{40}$. Thus, the $\mathrm{EtOH}$-induced fusion suppression might involve modification of cardiolipin but because of the wide range of cardiolipin-dependent processes, this possibility is difficult to directly test.

Whereas reduced mitochondrial fusion in VL-17A was independent of fusion proteins levels, we showed that in skeletal muscle fibers ${ }^{16}$ extracted from chrEtOH-fed rats, mitochondrial fusion was suppressed through a decrease in MFN1 protein level. Both skeletal muscle and brain have little capacity to metabolize EtOH. Dysregulation of $\Delta \Psi_{\mathrm{m}}$ or $\mathrm{Ca}^{2+}$ transport could also cause a decrease in mitochondrial fusion. In hepatocytes isolated from EtOH-fed animals, Gaspers et al. ${ }^{41}$ reported higher levels and uptake of mitochondrial $\mathrm{Ca}^{2+}$, attributed to higher expression of VDAC (voltage-dependent anion channel) and MCU (mitochondrial $\mathrm{Ca}^{2+}$ uniporter) proteins. However, in VL-17A or HepG2 cells, EtOH treatment did not change mitochondrial $\mathrm{Ca}^{2+}$ uptake or $\Delta \Psi_{\mathrm{m}}$ excluding the role of these factors in fusion inhibition.

Toxicity depends on the concentration and exposure time of EtOH. High doses of $\mathrm{EtOH}$ lead to mitochondrial $\mathrm{Ca}^{2+}$ overload, $\Delta \Psi_{\mathrm{m}}$ dissipation, release of cyto c, and cell death $^{42}$. In this study, $80-100 \mathrm{mM}$ EtOH for $48-72 \mathrm{~h}$ caused only a small increase in cell death in HepG2 cells. No sign of PTP formation or cyto c release were detected, as in ${ }^{43,44}$. However, we showed that $\mathrm{EtOH}$ sensitizes HepG2 cells to tBid-induced OMMP and cell death. Pastorino et al. ${ }^{45}$ have already shown that $\mathrm{EtOH}$ can potentiate mitochondrial membrane permeabilization by TNF- $\alpha$, upstream of tBid in HepG2 cells, however; they showed that this effect is independent of caspase-8, which is needed for activation of Bid to tBid. Thus, EtOH seems to sensitize cells to TNF- $\alpha$-dependent pathways in multiple ways. Along this line, it is likely that $\mathrm{EtOH}$ would affect mitochondrial cell death induced by drugs with many cellular targets, including the Bak/Bax pathways like staurosporine and etoposide but this effect would not be specific to the tBid-Bak pathway.

EtOH can directly target cellular membranes and causes disordering, disrupting, or altering of the physical shape of the membrane and therefore changing the ultrastructure of mitochondria. However, as short-term EtOH exposure does not promote tBid-induced OMMP in HepG2 cells, acute effects on the membranes are not the reason for $\mathrm{EtOH}$-induced sensitivity to tBid. As cyto c is located in the cristae, it is possible that $\mathrm{EtOH}$-induced morphology impairs the interaction between cyto $\mathrm{c}$ and its binding partner in IMM. In animals, chrEtOH stiffens the membranes by increasing cholesterol and saturated lipids $^{13}$. In mitochondrial membranes, cardiolipin confers resistance to $\mathrm{EtOH}^{36}$. The potential alterations in lipids may be relevant for the tBid-induced OMMP. On the other hand, EtOH might interact with proteins in the membrane and change their conformation ${ }^{46}$. Indeed, in another paradigm, $\mathrm{EtOH}$ has been described to associate with phospholipase $\mathrm{C}$ and interfere with PLC/D mediated signal transduction ${ }^{47,48}$.

EtOH has been described to alter Bcl-2 family proteins at the level of mRNA or protein ${ }^{42,49-52}$. However, we only found Bax levels affected in VL-17A. Furthermore, EtOH has been proposed to affect the post-translational modification of proteins in non-metabolizing cells ${ }^{53,54}$ that might also contribute to tBid-induced OMMP. Recently, Sariyer et al. ${ }^{55}$ showed that in neuronal cells chrEtOH exposure causes Mcl-1 missplicing and reduces the antiapoptotic isoform of Mcl-1 but our data did not show this in HepG2 cells. The most relevant mechanistic finding here was that chrEtOH facilitated the tBid-induced Bak oligomerization that alone can explain the increased OMMP in HepG2 cells.

$\mathrm{EtOH}$ has been reported to enhance membrane permeability of mitochondria isolated from hepatocytes upon stimuli like high $\mathrm{Ca}^{2+}$, Bax protein, Ceramide etc ${ }^{56}$. Because EtOH-metabolizing VL-17A cells display elevated ROS and ROS were shown to sensitize the cells to tBid-induced cell death ${ }^{27}$, EtOH was anticipated to potentiate tBid/Bak-induced death in VL-17A cells. This idea was also supported by data on VL-17A cells that upon exposure to EtOH, oxidative stress, caspase 3 activation, and cell death were observed ${ }^{44,57}$. Surprisingly, we found that chrEtOH exposure desensitized VL-17A to tBid-induced OMMP. Bax, a target of tBid is high in VL-17A cells but, Bax was reduced after chrEtOH like in hypoxia/reoxygenated brain $^{58}$, providing a plausible explanation for inhibition of tBid-induced OMMP. It is worth noting that VL-17A treated with EtOH showed less mitochondrial connectivity and dynamics (Fig. 1) and in the same condition, it showed less Bax level and therefore less sensitivity to tBid-induced OMMP (Fig. 9). These two 
responses are not in conflict with each other as, e.g., mitochondria in Mfn1/2 KO MEFs are desensitized to tBid-induced OMMP ${ }^{59}$. Furthermore, Hoppins et al. ${ }^{60}$ showed that cytosolic Bax positively regulates mitochondrial fusion, which might explain that a decrease in both total Bax and elongated mitochondria appear together in EtOH-treated VL-17A cells. In addition, fragmentation is not necessarily less healthy condition, e.g., in the prosurvival phenomenon of autophagy mitochondrial fragmentation seems to be necessary ${ }^{61}$.

Our work described two different effects of chrEtOHinduced stress on mitochondria, which are oppositely dependent on EtOH metabolism. ChrEtOH by itself can exert some suppression of mitochondrial fusion but products of EtOH metabolism, acetaldehyde and ROS, exert a more profound inhibition. On the other hand, EtOH by itself sensitizes Bid-induced apoptosis independent of ROS and the products of $\mathrm{EtOH}$ metabolism seem to have an opposite effect. These observations might have medical significance in the injury of the various tissues in alcoholics. The metabolism-dependent effects have to be most prominent in the liver, whereas the ones caused by $\mathrm{EtOH}$ by itself should dominate in skeletal-or cardiac muscle. Although we got some clues to the targeting of MFN1 and BAK by EtOH, further efforts will be needed to decide if alteration of lipid profiles or post-translational modification of proteins plays a role in these mitochondrial stress responses.

\section{Materials and methods Chemicals}

Cell permeable Bid $\mathrm{BH} 3$ peptide (Bid $\mathrm{BH} 3_{\mathrm{cp}}$ ) ([Arg](9)Gly-Glu-Asp-Ile-Ile-Arg-Asn-Ile-Ala-Arg-His-Leu-Ala-

Gln-Val-Gly-Asp-Ser-Met-Asp-Arg) was purchased from Selleckchem. tBid was produced as described ${ }^{29}$. Bismaleimidohexane (BMH) was from Pierce. G418 was from Enzo, Zeocin from Invitrogen. ALDA-1 from Tocris. Other chemicals except the specified ones were from Sigma.

\section{Cell lines, medium, and treatments}

HepG2 cells (ATCC) were grown in minimum essential medium (ATCC) supplemented with $10 \%$ fetal bovine serum (FBS) (Gibco), $100 \mathrm{U} / \mathrm{ml}$ penicillin, $100 \mu \mathrm{g} / \mathrm{ml}$ streptomycin, and $2 \mathrm{mM}$ Glutamine (Gibco) and kept in $37^{\circ} \mathrm{C}$ and $5 \% \mathrm{CO} 2$. Two modified HepG2 cell lines: (1) VL-17A cells expressing active murine alcoholic dehydrogenase class I (ADH) and human cytochrome P4502E1 (CYP2E1) similar to normal hepatocytes, and (2) VI-7 cells, that carry only one empty vector $\left(Z_{e o c i n}{ }^{+}\right)$ were from Dr. Dahn Clemens (Nebraska University, Omaha) ${ }^{23,44,62}$. VI-7 and VL-17A were cultured in the same medium as HepG2 with $400 \mu \mathrm{g} / \mathrm{ml}$ Zeocin for both (1) and (2) and with $400 \mu \mathrm{g} / \mathrm{ml} \mathrm{G418}$ antibiotics for (1). As neither HepG2 nor VI-7 show ADH and CYP2E1 activity and both cell lines show negligible EtOH metabolism activity $^{21,22}$ (Figure S1), and similar mitochondrial dynamic activity (Figure S2) the presence of Zeocin in the culture medium does not seem to alter these activities and in the study of mitochondrial dynamics (Figs. 1-5) we could use HepG2 cells as the primary control. In the study of tBid sensitivity both HepG2 (Figs. 6-8) and VI-7 (Fig. 9) cells were used as control for VL-17A cells.

H9c2 cells (ATCC) were maintained as it was described before $^{20,27}$. In acute treatments, $50-100 \mathrm{mM} \mathrm{EtOH}$ was added immediately before the experiment and in chronic treatments $50-100 \mathrm{mM}$ EtOH was added for $48-72 \mathrm{~h}$ to the cells medium with every $12 \mathrm{~h}$ refreshments and every $24 \mathrm{~h}$ replacement. Plates were sealed to avoid EtOH evaporation. Trolox $(50 \mu \mathrm{M})$, 4-MP $(5 \mathrm{mM})$, and ALDA-1 $(0.010 \mathrm{mM})$ treatments were performed at the same time as $\mathrm{EtOH}$ was administered.

\section{Transient expression}

DNA transfection was performed using either XTremeGene9 (Roche) or Lipofectamine 3000 (Invitrogen) in accordance with the manufacturers' protocols $24-48 \mathrm{~h}$ before imaging. The following plasmids were used: mtDsRed (Takara Bio Inc.) and mtPA-GFP ${ }^{63}$, which used the targeting sequence of cyto c oxidase subunit VIII. Grx1-roGFP2 ${ }^{64}$, which is targeted to either cytosol or mitochondria using a signal sequence from Neurospora crassa ATP synthase protein 9.

\section{Live-cell microscopic imaging}

Fluorescence spreading experiments were performed on a LSM780 microscope with a $\times 63$ oil objective (Carl Zeiss), recording $512 \times 512$ pixel image pairs at $0.25 \mathrm{~s}^{-1}$. A Chameleon laser (760 nm, Coherent) was used for twophoton photoactivation of mtPA-GFP ${ }^{25}$. An argon laser source was used for imaging of mtPA-GFP at $488 \mathrm{~nm}$ and a DPSS laser at $568 \mathrm{~nm}$ for mtDsRed (Takara Bio). Image analysis was performed using Spectralyzer (MitoCare proprietary) software and/or Image-J (imagej.nih.gov).

ROS measurements were performed with an inverted epifluorescence microscope (Olympus) with a $\times 40$ oil objective connected to a cooled CCD camera (PXL, Photometrics). Ratiometric imaging was performed at $490 \mathrm{~nm}$ and $415 \mathrm{~nm}$, recording $512 \times 512$ or $256 \times 256$ pixel image pairs at $0.1 \mathrm{~s}^{-1}$. Calibration of the probe was performed by adding $2 \mathrm{mM}$ DTT for minimal ratio value and $0.2 \mathrm{mM} \mathrm{H}_{2} \mathrm{O}_{2}$ for maximal ratio value. All the experiments were performed in extracellular matrix containing $0.25 \%$ bovine serum albumin at $37^{\circ} \mathrm{C}$.

\section{Bioluminescent viability assay}

HepG2 cells were seeded in 24-well plate (24,000/well), treated with $\mathrm{EtOH}$ as it described in "Cell lines, medium, and $\mathrm{EtOH}$ treatment". In the last $2 \mathrm{~h}$, cells were treated 
with Bid BH3cp in the cell medium described above except that it was supplemented with $2 \%$ FBS. The cell viability measured using CellTiter-Glo Luminescent Cell Viability Assay (Promega).

\section{$\Delta \Psi_{m}$ measurement, cyto c release assay, and $\mathrm{Ca}^{2+}$ recording in cell suspension}

$\Delta \Psi_{\mathrm{m}}$ was recorded using fluorometer (DeltaRAM; Horiba, NewJersey, USA) with either TMRM $(1.5 \mu \mathrm{M})$ or JC-1 $(0.8 \mu \mathrm{M})$ as described ${ }^{27,65,66}$. Cells were harvested and washed with cold Na-Hepes-EGTA buffer containing

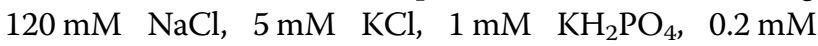
$\mathrm{MgCl}_{2}$, and $20 \mathrm{mM}$ Hepes- $\mathrm{NaOH}, \mathrm{pH} 7.4$. In $37^{\circ} \mathrm{C}$ and under stirring condition, the same aliquots of cells $(1.2-2.4 \mathrm{mg})$ were permeabilized using $30-40 \mu \mathrm{g} / \mathrm{ml}$ Digitonin in $1.5 \mathrm{ml}$ intracellular medium buffer (ICM:120

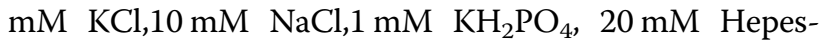
Tris, $\mathrm{pH}$ 7.2) supplemented with $5 \mu \mathrm{g} / \mathrm{ml}$ protease inhibitors leupeptin, antipain, and pepstatin for $5 \mathrm{~min}$. In all the experiments, $2 \mathrm{mM}$ MgATP, $2 \mathrm{mM}$ succinate, and 5 $\mu \mathrm{g} / \mathrm{ml}$ oligomycin were present. Digitonin $600 \mu \mathrm{g} / \mathrm{ml}$ was used to release total cyto $\mathrm{c}$ from the mitochondria. Uncoupler, FCCP $(5 \mu \mathrm{M})$ was applied at the end of each run to dissipate remaining $\Delta \Psi_{\mathrm{m}}$. JC-1 was used as the ratio of the aggregated dye intensity $(570 \mathrm{~nm}$ excitation/ $595 \mathrm{~nm}$ emission) to monomeric dye (490 nm excitation/ $535 \mathrm{~nm}$ emission) and TMRM with $540 \mathrm{~nm}$ excitation and $580 \mathrm{~nm}$ emission. After each run samples were centrifuged for $5 \mathrm{~min}$ at $10,000 \times g$ and cytosolic and membrane fractions were separated. For $\mathrm{Ca}^{2+}$ measurements, $2 \mu \mathrm{M}$ thapsigargin (Enzo) and $1.0 \mu \mathrm{M}$ fura2FF ( $K d=4.5$ $\mu \mathrm{M}$, TEFLabs) were added to ICM, which was supplemented as explained above without oligomycin. Calibration for maximum and minimum fura2FF response was performed by adding $1 \mathrm{mM} \mathrm{Ca}^{2+}$ and $10 \mathrm{M}$ EGTA/TRIS $\mathrm{pH} 8.5$, respectively.

\section{Western blotting}

Intact cells or membrane fraction (pelleted by centrifuging permeabilized cell suspensions at 10,000 $\times g$ for $5 \mathrm{~min}$ ) were lysed in cold radioimmunoprecipitation assay buffer, (150 mM NaCl, 1.0\% (vol/vol) Octylphenoxypolyethoxyethanol, $0.5 \%$ sodium deoxycholate, $0.1 \%$ sodium dodecyl sulphate, and $50 \mathrm{mM}$ Tris $(\mathrm{pH} 8.0$; Sigma)), supplemented with $1 \mu \mathrm{g} / \mathrm{ml}$ protein inhibitors (leupeptin, antipain, and pepstatin) and $1 \mathrm{mM}$ phenylmethylsulfonyl fluoride. Lysed samples and cytosol fractions were used for immunoblotting. Western blot was performed based on instructions of LI-COR (LI-COR Corporation, Nebraska, USA). Primary antibodies used were Anti-BAK (no. 06-536; Millipore) Anti-cyto c (no. 556433; BD Bioscience), Anti-HA (no. 9110; Abcam), Anti-mtHsp70 (no. MA3-028; Thermo Scientific), and Anti-prohibitin (no. ab28172; Abcam), anti-Bax (N-20, sc-
493, SantaCruz), anti-MCL-1 (ADI-AAP-240, Enzo life sciences), anti-Bid (no. AF860, R\&D systems), anti-Bim (no.2933, Cell Signaling), anti-Bcl-xL (no. 610211, BD transduction), anti-Actin (no.612656, BD transduction), anti-Calnexin (no. ADI-SPA-860, Enzo Life sciences). Detection of bands was performed on a LI-COR Odyssey scanner. ImageJ was used for quantification of the bands.

\section{Oligomerization assay}

Oligomerization has been performed as described previously $^{27}$. In brief, pellet fractions from " $\Delta \Psi_{\mathrm{m}}$ measurement and cyto c Release Assay" section were treated with $10 \mathrm{mM}$ freshly prepared cross-linker, $\mathrm{BMH}$, for $30 \mathrm{~min}$ and then reaction was stopped with $20 \mathrm{mM}$ Tris (pH 7.5). Samples were lysed as described in western blot section.

\section{Statistics}

Samples were run as duplicates or triplicates. All experiments were repeated at least three times. Statistical significance was calculated using two-way ANOVA.

\section{Acknowledgments}

We thank Mr. David Weaver for his technical assistance, Drs. Erin Seifert and Jan Hoek for reading the manuscript/their advices, and Dr. Arthur Cederbaum for personal contact and advice on CYP2E1 enzyme activity protocol. This work has been supported by NIH grant U01AA021122, to GH and ER.

Conflict of interest

The authors declare that they have no conflict of interest.

\section{Publisher's note}

Springer Nature remains neutral with regard to jurisdictional claims in published maps and institutional affiliations.

Supplementary Information accompanies this paper at (https://doi.org/ 10.1038/s41419-018-1070-3).

Received: 5 December 2017 Revised: 29 June 2018 Accepted: 20 August 2018

Published online: 09 October 2018

\section{References}

1. Santel, A. \& Fuller, M. T. Control of mitochondrial morphology by a human mitofusin. J. Cell Sci. 114, 867-874 (2001).

2. Cipolat, S., Martins de Brito, O., Dal Zilio, B. \& Scorrano, L. OPA1 requires mitofusin 1 to promote mitochondrial fusion. Proc. Natl. Acad. Sci. USA 101, 15927-15932 (2004)

3. Otera, H., Ishihara, N. \& Mihara, K. New insights into the function and regulation of mitochondrial fission. Biochim. Biophys. Acta 1833, 1256-1268 (2013).

4. Chen, $\mathrm{H}$. et al. Mitofusins Mfn1 and Mfn2 coordinately regulate mitochondrial fusion and are essential for embryonic development. J. Cell Biol. 160, 189-200 (2003).

5. Zuchner, S. et al. Mutations in the mitochondrial GTPase mitofusin 2 cause Charcot-Marie-Tooth neuropathy type 2A. Nat. Genet. 36, 449-451 (2004).

6. Alexander, C. et al. OPA1, encoding a dynamin-related GTPase, is mutated in autosomal dominant optic atrophy linked to chromosome 3q28. Nat. Genet. 26, 211-215 (2000)

7. Delettre, $C$. et al. Nuclear gene OPA1, encoding a mitochondrial dynaminrelated protein, is mutated in dominant optic atrophy. Nat. Genet. 26, 207-210 (2000). 
8. Rasola, A. \& Bernardi, P. Mitochondrial permeability transition in $\mathrm{Ca}(2+)$ dependent apoptosis and necrosis. Cell Calcium 50, 222-233 (2011).

9. Chi, X., Kale, J., Leber, B. \& Andrews, D. W. Regulating cell death at, on, and in membranes. Biochim. Biophys. Acta 1843, 2100-2113 (2014).

10. Tait, S. W. \& Green, D. R. Mitochondria and cell death: outer membrane permeabilization and beyond. Nat. Rev. Mol. Cell Biol. 11, 621-632 (2010).

11. Osna, N. A. et al. Aberrant post-translational protein modifications in the pathogenesis of alcohol-induced liver injury. World J. Gastroenterol. 22, 6192-6200 (2016).

12. Zakhari, S. Overview: how is alcohol metabolized by the body? Alcohol Res. Health 29, 245-254 (2006).

13. Goldstein, D. B. Effect of alcohol on cellular membranes. Ann. Emerg. Med. 15 1013-1018 (1986).

14. Cederbaum, A. I., Lu, Y. \& Wu, D. Role of oxidative stress in alcohol-induced liver injury. Arch. Toxicol. 83, 519-548 (2009).

15. Hoek, J. B., Cahill, A. \& Pastorino, J. G. Alcohol and mitochondria: a dysfunctional relationship. Gastroenterology 122, 2049-2063 (2002).

16. Eisner, V., Lenaers, G. \& Hajnoczky, G. Mitochondrial fusion is frequent in skeletal muscle and supports excitation-contraction coupling. J. Cell Biol. 205, 179-195 (2014).

17. Das, S. et al. Mitochondrial morphology and dynamics in hepatocytes from normal and ethanol-fed rats. Pflug. Arch. 464, 101-109 (2012).

18. King, A. L. et al. Involvement of the mitochondrial permeability transition pore in chronic ethanol-mediated liver injury in mice. Am. J. Physiol. Gastrointest. Liver Physiol. 306, G265-G277 (2014).

19. Hajnoczky, G., Buzas, C. J., Pacher, P., Hoek, J. B. \& Rubin, E. Alcohol and mitochondria in cardiac apoptosis: mechanisms and visualization. Alcohol. Clin. Exp. Res. 29, 693-701 (2005).

20. Pacher, P. \& Hajnoczky, G. Propagation of the apoptotic signal by mitochondrial waves. EMBO J. 20, 4107-4121 (2001).

21. Clemens, D. L., Halgard, C. M., Miles, R. R., Sorrell, M. F. \& Tuma, D. J. Establishment of a recombinant hepatic cell line stably expressing alcohol dehydrogenase. Arch. Biochem. Biophys. 321, 311-318 (1995).

22. Dai, Y., Rashba-Step, J. \& Cederbaum, A. I. Stable expression of human cytochrome P4502E1 in HepG2 cells: characterization of catalytic activities and production of reactive oxygen intermediates. Biochemistry 32, 6928-6937 (1993).

23. Clemens, D. L., Forman, A., Jerrells, T. R., Sorrell, M. F. \& Tuma, D. J. Relationship between acetaldehyde levels and cell survival in ethanol-metabolizing hepatoma cells. Hepatology 35, 1196-1204 (2002).

24. Gal, A. et al. MSTO1 is a cytoplasmic pro-mitochondrial fusion protein, whose mutation induces myopathy and ataxia in humans. EMBO Mol. Med. 9, 967-984 (2017).

25. Liu, X., Weaver, D., Shirihai, O. \& Hajnoczky, G. Mitochondrial 'kiss-and-run': interplay between mitochondrial motility and fusion-fission dynamics. EMBO J. 28, 3074-3089 (2009).

26. Song, Z., Chen, H., Fiket, M., Alexander, C. \& Chan, D. C. OPA1 processing controls mitochondrial fusion and is regulated by mRNA splicing, membrane potential, and Yme1L. J. Cell Biol. 178, 749-755 (2007).

27. Garcia-Perez, C. et al. Bid-induced mitochondrial membrane permeabilization waves propagated by local reactive oxygen species (ROS) signaling. Proc. Natl Acad. Sci. USA 109, 4497-4502 (2012).

28. Goldsmith, K. C. et al. BH3 peptidomimetics potently activate apoptosis and demonstrate single agent efficacy in neuroblastoma. Oncogene $\mathbf{2 5}, \mathbf{4 5 2 5 - 4 5 3 3}$ (2006).

29. Desagher, S. et al. Bid-induced conformational change of Bax is responsible for mitochondrial cytochrome c release during apoptosis. J. Cell Biol. 144, 891-901 (1999).

30. Oettinghaus, B. et al. DRP1-dependent apoptotic mitochondrial fission occurs independently of BAX, BAK and APAF1 to amplify cell death by BID and oxidative stress. Biochim. Biophys. Acta 1857, 1267-1276 (2016).

31. Lee, Y. J., Jeong, S. Y., Karbowski, M., Smith, C. L. \& Youle, R. J. Roles of the mammalian mitochondrial fission and fusion mediators Fis1, Drp1, and Opa1 in apoptosis. Mol. Biol. Cell 15, 5001-5011 (2004).

32. Frezza, C. et al. OPA1 controls apoptotic cristae remodeling independently from mitochondrial fusion. Cell 126, 177-189 (2006).

33. Assiri, M. A. et al. Chronic ethanol metabolism inhibits hepatic mitochondrial superoxide dismutase via lysine acetylation. Alcohol Clin. Exp. Res. 41, 1705-1714 (2017)
34. Teplova, V. V. et al. Glutamate contributes to alcohol hepatotoxicity by enhancing oxidative stress in mitochondria. J. Bioenerg. Biomembr. 49, 253-264 (2017).

35. Vay, D. et al. Anti-phospholipid antibodies associated with alcoholic liver disease target oxidized phosphatidylserine on apoptotic cell plasma membranes. J. Hepatol. 44, 183-189 (2006).

36. Ellingson, J. S., Taraschi, T. F., Wu, A., Zimmerman, R. \& Rubin, E. Cardiolipin from ethanol-fed rats confers tolerance to ethanol in liver mitochondrial membranes. Proc. Natl Acad. Sci. USA 85, 3353-3357 (1988).

37. Ban, T. et al. Molecular basis of selective mitochondrial fusion by heterotypic action between OPA1 and cardiolipin. Nat. Cell Biol. 19, 856-863 (2017).

38. Choi, S. Y. et al. A common lipid links Mfn-mediated mitochondrial fusion and SNARE-regulated exocytosis. Nat. Cell Biol. 8, 1255-1262 (2006).

39. Kameoka, S., Adachi, Y., Okamoto, K. \& lijima, M. \& Sesaki, H. Phosphatidic acid and cardiolipin coordinate mitochondrial dynamics. Trends Cell Biol. 28, 67-76 (2018).

40. Ikon, N. \& Ryan, R. O. Cardiolipin and mitochondrial cristae organization. Biochim. Biophys. Acta 1859, 1156-1163 (2017)

41. Wang, G., Memin, E., Murali, I. \& Gaspers, L. D. The effect of chronic alcohol consumption on mitochondrial calcium handling in hepatocytes. Biochem. J. 473, 3903-3921 (2016).

42. Nakayama, N., Eichhorst, S. T., Muller, M. \& Krammer, P. H. Ethanol-induced apoptosis in hepatoma cells proceeds via intracellular $\mathrm{Ca}(2+)$ elevation, activation of TLCK-sensitive proteases, and cytochrome $c$ release. Exp. Cell Res. 269, 202-213 (2001).

43. Wu, D. \& Cederbaum, A. I. Ethanol cytotoxicity to a transfected HepG2 cell line expressing human cytochrome P4502E1. J. Biol. Chem. 271, 23914-23919 (1996).

44. Donohue, T. M., Osna, N. A. \& Clemens, D. L. Recombinant Hep G2 cells that express alcohol dehydrogenase and cytochrome P450 2E1 as a model of ethanol-elicited cytotoxicity. Int. J. Biochem. Cell. Biol. 38, 92-101 (2006).

45. Pastorino, J. G. \& Hoek, J. B. Ethanol potentiates tumor necrosis factor-alpha cytotoxicity in hepatoma cells and primary rat hepatocytes by promoting induction of the mitochondrial permeability transition. Hepatology $\mathbf{3 1}$ 1141-1152 (2000)

46. Franks, N. P. \& Lieb, W. R. Do general anaesthetics act by competitive binding to specific receptors? Nature 310, 599-601 (1984).

47. Higashi, K. \& Hoek, J. B. Ethanol causes desensitization of receptor-mediated phospholipase C activation in isolated hepatocytes. J. Biol. Chem. 266, 2178-2190 (1991)

48. Hoek, J. B., Thomas, A. P., Rooney, T. A., Higashi, K. \& Rubin, E. Ethanol and signal transduction in the liver. FASEB J. 6, 2386-2396 (1992)

49. Moore, D. B., Walker, D. W. \& Heaton, M. B. Neonatal ethanol exposure alters bcl-2 family mRNA levels in the rat cerebellar vermis. Alcohol. Clin. Exp. Res. 23, 1251-1261 (1999).

50. Mooney, S. M. \& Miller, M. W. Effects of prenatal exposure to ethanol on the expression of bcl-2, bax and caspase 3 in the developing rat cerebral cortex and thalamus. Brain Res. 911, 71-81 (2001).

51. Ge, Y., Belcher, S. M., Pierce, D. R. \& Light, K. E. Altered expression of Bcl2, Bad and Bax mRNA occurs in the rat cerebellum within hours after ethano exposure on postnatal day 4 but not on postnatal day 9. Brain. Res. Mol. Brain. Res. 129, 124-134 (2004)

52. King, A. L., Swain, T. M., Dickinson, D. A., Lesort, M. J. \& Bailey, S. M Chronic ethanol consumption enhances sensitivity to $\mathrm{Ca}(2+)$-mediated opening of the mitochondrial permeability transition pore and increases cyclophilin D in liver. Am. J. Physiol. Gastrointest. Liver Physiol. 299, G954-G966 (2010).

53. Shepard, B. D., Tuma, D. J. \& Tuma, P. L. Chronic ethanol consumption induces global hepatic protein hyperacetylation. Alcohol. Clin. Exp. Res. 34, 280-291 (2010).

54. Harris, P. S. et al. Chronic ethanol consumption induces mitochondrial protein acetylation and oxidative stress in the kidney. Redox Biol. 6, 33-40 (2015).

55. Sariyer, R. et al. Alcohol-mediated missplicing of Mcl-1 Pre-mRNA is involved in neurotoxicity. Alcohol Clin. Exp. Res. 41, 1715-1724 (2017).

56. Pastorino, J. G., Marcineviciute, A., Cahill, A. \& Hoek, J. B. Potentiation by chronic ethanol treatment of the mitochondrial permeability transition. Biochem. Biophys. Res. Commun. 265, 405-409 (1999).

57. Kim, T. H. et al. A novel small molecule, LAS-0811, inhibits alcohol-induced apoptosis in VL-17A cells. Biochem. Biophys. Res. Commun. 379, 876-881 (2009). 
58. Yuan, Y. et al. Ethanol reduces expression of apoptotic proteins after hypoxia/ reoxygenation in a brain slice model. Neurol. Res. 34, 373-378 (2012).

59. Weaver, D. et al. Distribution and apoptotic function of outer membrane proteins depend on mitochondrial fusion. Mol. Cell 54, 870-878 (2014).

60. Hoppins, S. et al. The soluble form of Bax regulates mitochondrial fusion via MFN2 homotypic complexes. Mol. Cell 41, 150-160 (2011).

61. Twig, G. \& Shirihai, O. S. The interplay between mitochondrial dynamics and mitophagy. Antioxid. Redox Signal. 14, 1939-1951 (2011).

62. Osna, N. A., Clemens, D. L. \& Donohue, T. M. Jr. Interferon gamma enhances proteasome activity in recombinant Hep G2 cells that express cytochrome P4502E1: modulation by ethanol. Biochem. Pharmacol. 66, 697-710 (2003).
63. Karbowski, M. et al. Quantitation of mitochondrial dynamics by photolabeling of individual organelles shows that mitochondrial fusion is blocked during the Bax activation phase of apoptosis. J. Cell Biol. 164, 493-499 (2004).

64. Gutscher, M. et al. Real-time imaging of the intracellular glutathione redox potential. Nat. Methods 5, 553-559 (2008).

65. Naghdi, S., Varnai, P. \& Hajnoczky, G. Motifs of VDAC2 required for mitochondrial Bak import and tBid-induced apoptosis. Proc. Natl Acad. Sci. USA 112, E5590-E5599 (2015).

66. Madesh, M., Antonsson, B., Srinivasula, S. M., Alnemri, E. S. \& Hajnoczky, G. Rapid kinetics of tBid-induced cytochrome $c$ and Smac/DIABLO release and mitochondrial depolarization. J. Biol. Chem. 277, 5651-5659 (2002). 